\title{
Protection the flavonoids, rutin and proto chatechuic acid, against mitotic crossing over, gene conversion and reverse mutation induced by (chlorpyritos) in Saccharomyces cerevisia D7.
}

\author{
Ekram,S. Ahmed \\ Department of Cell Biology, National Research Center Cairo - Egypt.
}

\begin{abstract}
Introduction: Protection by the flavonoids, rutin and protochatechuic acid, against insecticide chlorpyrifos induced mitotic crossing over, gene conversion and reverse mutation were investigated in Saccharomyces cerevisia D7 .

Results: The results indicate that Rutin and Protochatechuic acid have some antimutagenic potential against mutagenicity of chloropyrifos.

There for, the flavonoids contained in Senna seem to be important as antimutagenic and antioxidants.
\end{abstract}

\section{Introduction}

In many genetic investigation the organophosphorus insecticides has been reported as a potent genotoxic agents (Abdallah et al. (1973); Nafei et al. (1984); Salam et al. (1984); Mansour et al. (1988) and Rahaman et al. (2002) . The induction of mitotic crossing over in diploid yeast Saccharomyces cereviciae is strongly correlated with the mutagenic effects. These tests very sensitivily react with compounds which induce base-pair substitution as well as fram-shift mutations. This system has revealed the genetic activity of large number of carcinogens, pesticides, radiation and many other chemical mutagens (Siebert and Elsenbrand, (1974); Zimmermann et al., (1975); Altwaty (1999);Anjaria and Rao (2001) and Buschini et al.,(2003 and 2004) .

Flavonoids are widely distributed in the plant Kingdom and are strong antioxidants (NaKatani, 1990 and KayoKo et al., 1996).

The antimutagenic activity of some of the isolated flavonoids from Senna species against mutation in yeast, caused by insecticide, will be studied. The short term tests have been used to detect the various physical, chemical, and biological agents (Anuradha et al., 1996).More recently these same tests have been used to study the antimutagenicity of certain single chemical and complex chemical mixtures. We selected the diploid strain D7 of Saccharomyces crevisiae which was constructed by Zimmermann, (1975) Specifically to detect, mitotic gene conversions, revertants and mitotic crossing over. Many, naturally occurring compounds can have important effects on the consequences of exposure to mutagens and carcinogense.Food ingredients like flavonoids have been claimed to have antimutagenic or anticarcinigeneic potential (Steinmetz and Potter, 1991).

In this study the influence of quercetin glycoside, namely rutin also 3,4dihydroxy benzoic acid (protochatechuic acid) on insecticide chlorpyrifos induced mutations in Saccharomyces cerevisiae strain D7 are investigated.

\section{Materials and methods}

\section{1- Yeast strain}

The D7 strain of Saccharomyces cereviciae was used as a test organism (Courtesy of F.K. Zimmermann.Darmstad, Germany). This strain has the following genotype: ade2-40 / ade2-119. Trp512/trp5-27, ilvl-92/ilvl-92. It is used for the simultaneous detection of induced reverse mutation, mitotic gene conversion, 
and mitotic crossing over (Zimmermann et al., 1975).

\section{2-Chemicals}

a. The insecticide chlorpyrifos was obtained from Hanoo Agricultural, the sole agent in K.S.A,P.O. Box .4894 Riyadh 114412.Manufactured by ChemacAgriphar / Rue De Renory, 261B-41020 Ugree/Belgium. Chlorpyrifos is an organophosphorus insecticide, its chemical is:

O, O-diethylo-3, 5, 6 trichloro-2 pyridyl phosphorothioate.

b-Rutin and protochatechuic acid are isolated compounds from Senna spp (Cassia) (Leguminosae), obtained from Dr. Aisha Mohamed,Ali Khogli, Faculty of Science, King Abdelazizi University .

\section{3- Medium}

a. Complete medium

This medium was used for routine culture growth, it contains : peptone $5 \mathrm{mg} / \mathrm{L}$,yeast exract $10 \mathrm{~g} / \mathrm{L}$, glucose $20 \mathrm{~g} / \mathrm{L}$ and Agar 20 $\mathrm{g} / \mathrm{L}$.

b- Minimal medium

The medium components have been described in detail by Zimmermann et al.(1975).

\section{4- Testing assay}

a- Three concentrations were prepared from chlorpyriphos, these concentrations were $1,2,5 \mu 1$ per ml media .

b-The used concentration of rutin and protochatechuic acid are $5 \mu \mathrm{l}$ per $\mathrm{ml}$ media.

c- Combined trearment the used concentration of chlorpyriphos, rutin and protochatechuic acid for combined treatments was $5 \mu \mathrm{l} / \mathrm{ml}$ media.

\section{Treatment protocol}

1. $10 \mathrm{ml}$ of liquid complete medium were inoculated with about $5 \times 10$ cells $/ \mathrm{ml}$ in $50 \mathrm{ml}$ conical flask.

2. The culture was incubated on an orbital shaker water bath at $24 \mathrm{c}^{\circ}$ for 6 hrs.

3. The sample of the cell was examined under the microscope, the proper culture must be in experimental phase (at least $90 \%$ of the cells have buds).

4. Concentration series for treatment were inoculated cache with $1 \mathrm{ml}$ sample cells and incubated at $28 \mathrm{c}^{\mathrm{o}}$ on a water bath shaker for $18 \mathrm{hrs}$.

5. After appropriate dilution, the cells were plated onto :

i. Complete medium with cycloheximade to detect mitotic crossing over.

- Synthetic complete medium without tryptophan to detect gene conversion.

- Synthetic complete medium without isoleucine to detect

- Point mutation.

\section{Analysis and evaluation of the data}

The frequencies of gene conversion, reverse mutation and mitotic crossing over were computed by dividing the number of convertant, revertant and mitotic crossing over colonies. The general consensus was that increase in an end point under investigation up to two folds or more of the mean of control frequency is biologically considered as a significant response (Brusik, 1980).

\section{Results and discussion}

The result in table (1) show the genetic activities in such chlorpyriphos in Saccharos-myces cereviciae D7. Chlorpyriphos exhibited moderate toxicity at the lower concentration which proportionally increased by increasing the treatment dose $(1-5 \mu \mathrm{l} / \mathrm{ml})$. survival percentages ranged from $70 \%$ at the lowest concentration ( $1 \mu_{1 / \mathrm{ml}}$ ) to $27 \%$ at highest one ( $5 \mu 1 / \mathrm{ml})$. Weak positive mutagenic activity was obtained using the concentration $1 \mu 1 / \mathrm{ml}$ where the induced frequency of mitotic crossing over at the cyclohexamide (Cyh) locus was 4.7 times the spontaneous frequency, While the same concentration showed negative result in the induction of gene conversion at the tryptophan-5 (Trp-5) locus and reversion at isoleucine (il) locus.. Also, moderate mutagenic activity was obtained at the three loci under study when chlorpyriphos applied at the concentration $2 \mu \mathrm{l} / \mathrm{ml}$ which resulted in mitotic crossing over in frequency 3.6, 4.1 and 9.6 times the spontaneous ones respectively. Chlorpyriphos as a mutagen proved to be more 


\section{Ekram,S. Ahmed}

potent at the concentration $5 \mu 1 / \mathrm{ml}$ which caused $27 \%$ survival and resulted in mitotic gene conversion, reversion and mitotic crossing over in frequencies 13.1,13.2 and 20 times of control ones respectively. These result suggest the mutagenic effect of chlorpyriphos in the induction of conversion of convertant, revertant and mitotic crossing over in Saccharos-myces cereviciae, strain D7. This is in agreement with the results obtained by many reports used pesticides in Saccharos-myces cereviciae, El-Adawy et al.(1998);Salam et al.(1993 and 1995); Ahmed et al. (1999) and Al-twaty (1999). Results of rutin one of the quercetin glycosides are shown in table (2) exhibited the genetic activities of rutin in S.cerevisiae strain D7 .Rutin exerted a weak recornbinogenic activity. which resulted in revertants in frequency 2.3 times as the control levels. While, using the same concentration it did not induce gene conversion and mitotic crossing over. Mean While, moderate mutagenic activity was obtained at the combined treatment of rutin and chlorpyrifos, resulted in mitotic gene conversion and mitotic crossing over in frequencies of 3.3 and 2.6 times the spontaneous ones respectively while the same treatment was inducing revertants in a frequency of 10.3 the control level. This results suggests that rutin was capable of inducing only revertants in a weak frequency of 2.3 the control level, but did not induce mitotic gene convrsion or mitotic crossing, over. The combind treatment with the two substances led to an anti mutagenic effect, whereas a frequencies of gene conversion, revertants and mitotic crossing over with the combined treatment was slightly lower as compared with chlorpyrifos alone.

A satisfactory contribution to the understanding of the antimutagenic effect of rutin was obtained by using the D7 strain of $S$. cenrevisiae. The effect of rutin in eukaryotic systems was not clear and the results were contradictory. In strain D7 rutin reduces mitotic gene conversion and mitotic crossing-over induced by chlorpyrifos. The most likely hypothesis is that rutin exerts its effect in repair processes of the DNA. The results obtained with rutin in strain D7 of $S$. cerevisiae are in agreement with Giorgio et al. (1992) who found that the spermine reduces point mutation and mitotic gene conversion induced by agents with different mechanisms of action using the D7 strain of S.cerevisiae. Also Bear and TeeL (2000) found that heterocyclic amines (Melqx and G'lu-p-1) induced mutagensis in Salmonella typhimurium, were significantly inhibited by flavonoid (rutin).Moreover, Horcajada-Molteni et al.(2000) reported that rutin inhibtes ovariectomy induced osteopenia in rats . Edenharder and Grunhage (2003). conclude that in the Salmonellal reversion assay, antimutagenic activities of rutin against the peroxide mutagens are caused by radical scavenging effects. In human Lymphocytes rutin displayed protective effects on DNA damage induced by mitomycin C (Undeger et al., 2004).Also , Stagos et al ., (2005) reported that protovatechuic acid and rutin act as chemopreventive agents by inhibiting mitomycin C-induced DNA damage .

Results in table (3) showed the genetic activities of 3.4-dihydroxybenzoic acid and its combined with chlorpyrifos.3.4- dihydroxybenzoic acid exerted a weak recombinogenic activity when applied at the concentration of $5 \mathrm{ul} / \mathrm{ml}$, which resulted in mitotic gene conversion and mitotic crossing-over in frequencies of 3.8 and 6.8 times as the control levels, respectively. While, using the same concentration of 3.4-dihydroxy benzoic acid showed strong positive indications of mutagenic activity where the induced frequency of reversion was 12 times the spontaneous frequency.

The combined treatment was slightly lower as compared with chlorpyrifos alone, whereas a frequencies of gene conversion and mitotic crossingover was 7 and 6.5 times the control level in combined treatment, but the treatment of chlorpyrifos a frequencies of gene conversion and mitotic crossing-over were 13.4 and 20.5 times the control ones respectively .

The result of the present study show that rutin and 3,4-dihydroxybenzoic acid may prevent binding of metabolicaly 
activated of insecticide chlorpyrifos with DNA and inhibit its mutagenicity. Also synergism is an effect which intensifies the antimutagenic activity during simultaneous application of two or more compounds in genetic tests. It is important to elucidate the possibility of strengthening the antimutagenic potency of already known substances (Andrew,1997 and Shimoi et al. (1996) the defence systems of organisms that restrict the level of undesirable mutation processes. Flavonoids may be essential substancec for these roles . Moreover, organism defense systems may be protecting organisms from exogenous and endogenous DNA defeating factors,synergism may be the maim principle of defense system organization .

To summarize, the present results indicate that rutin and 3,4-di hydroxybenzoic acid have some antimutagenic potential. In the future, more studies are needed to establish more firmly the possible antimutagenic effects of flavonoids .

Table (1) Response of Saccharomyces cerevisiae D7 to treatment with different concentration of chlorpyrifos

\begin{tabular}{|c|c|c|c|c|c|c|c|c|c|c|}
\hline \multirow{2}{*}{$\begin{array}{l}\text { Xov. } \\
\boldsymbol{\mu}_{/ \mu \lambda}\end{array}$} & \multirow[b]{2}{*}{$\begin{array}{c}\text { Nu} \mu \beta \varepsilon \rho \text { o } \phi \\
\chi \varepsilon \lambda \lambda \sigma\end{array}$} & \multicolumn{3}{|c|}{$\mathrm{Xov} \varpi \varepsilon \rho \tau \alpha \nu \tau$} & \multicolumn{3}{|c|}{ 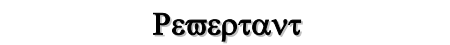 } & \multicolumn{3}{|c|}{$\mathrm{X} \rho \circ \sigma \sigma \imath v \gamma-о \varpi \varepsilon \rho$} \\
\hline & & $\operatorname{Mv\tau } \Phi \rho \varepsilon \theta$ & $\mathrm{T} / \chi$ & $\Delta . \mathrm{o} \phi \mathrm{A} \chi \tau$ & 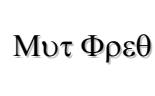 & $\mathrm{T} / \chi$ & $\Delta . \circ \phi \mathrm{A} \chi \tau$ & $\mathrm{M} \nu \tau \Phi \rho \varepsilon \theta$ & $\mathrm{T} / \chi$ & $\Delta . \circ \phi \mathrm{A} \chi \tau$ \\
\hline 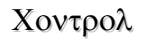 & 17084 & $14.1(24)$ & 1 & - & $11.7(20)$ & 1 & - & $16.4(28)$ & 1 & - \\
\hline $1 \mu \lambda$ & 10930 & $25.6(28)$ & 1.8 & - & $21.9(24)$ & 1.8 & - & $76.8(84)$ & 4.7 & + \\
\hline $2 \mathrm{M} \lambda$ & 7570 & $52.6(40)$ & 3.6 & + & $47.5(36)$ & 4.1 & + & $158.5(120)$ & 9.6 & + \\
\hline $5 \mathrm{M} \lambda$ & 4642 & $189.6(88)$ & 13.1 & ++ & $155.2(72)$ & 13.2 & ++ & $336.2(156)$ & 20 & ++ \\
\hline
\end{tabular}
Key: Con. $=$ Concentration
$\mathrm{T}=$ treatment value
Mut. = Mutation
- =non significant
$+=2-10$ control level
$\mathrm{C}=$ control value
of Act $=$ Degree of
$\square$
Table (2) Response of Saccharomyces cerevisiae D7 to treatment with rutin and its combined with chlorpyrifos

\begin{tabular}{|c|c|c|c|c|c|c|c|c|c|c|}
\hline \multirow[b]{2}{*}{$\begin{array}{l}\text { Xov. } \\
\mu_{/ \mu \lambda}\end{array}$} & \multirow[b]{2}{*}{$\begin{array}{c}\text { Nu} \mu \beta \varepsilon \rho \text { o } \phi \\
\chi \varepsilon \lambda \lambda \sigma\end{array}$} & \multicolumn{3}{|c|}{ 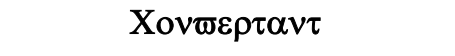 } & \multicolumn{3}{|c|}{ 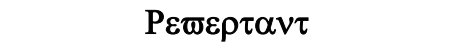 } & \multicolumn{3}{|c|}{ 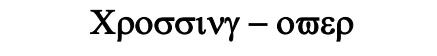 } \\
\hline & & 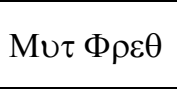 & $\mathrm{T} / \chi$ & $\Delta . \circ \phi \mathrm{A} \chi \tau$ & 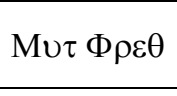 & $\mathrm{T} / \chi$ & $\Delta . \circ \phi \mathrm{A} \chi \tau$ & 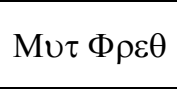 & $\mathrm{T} / \chi$ & $\Delta . \mathrm{o} \phi \mathrm{A} \chi \tau$ \\
\hline Xov $\tau \rho \circ \lambda$ & 17084 & 14.1(24) & 1 & - & $11.7(20)$ & 1 & - & $16.4(28)$ & 1 & - \\
\hline${ }_{5} \stackrel{X}{\mu}_{\lambda / \mu \lambda}$ & 4642 & 189.6(88) & 13.1 & ++ & $155.2(72)$ & 13.2 & ++ & $336.2(156)$ & 20 & ++ \\
\hline 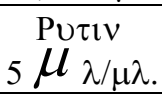 & 18512 & $16.8(31)$ & 1.2 & - & $27.55(51)$ & 23 & + & $26.47(49)$ & 1.6 & - \\
\hline Хон Т $\rho$. & 10180 & $46.17(47)$ & 3.3 & + & $120.8(123)$ & 10.3 & ++ & $42.2(43)$ & 2.6 & + \\
\hline
\end{tabular}

Key : Con. $=$ Concentration ,Mut.=Mutation;

D. of Act $=$ Degree of activity $;$ Numbers. between

Parentheses represents actual colony counts; $\mathrm{C}=$

Control value; $\mathrm{T}=$ Treatment value; $+=2-10$ control

Chlopyrifos;com. Tr. = combined treatment . 


\section{Ekram,S. Ahmed}

Table (3) Response of Saccharomyces cerevisiae D7 to treatment protochatechuic acid and its combined with chlorpyrifos

\begin{tabular}{|c|c|c|c|c|c|c|c|c|c|c|}
\hline \multirow[b]{2}{*}{$\begin{array}{l}\text { Xov. } \\
\mu_{/ \mu \lambda}\end{array}$} & \multirow[b]{2}{*}{$\begin{array}{c}\text { Nu} \mu \beta \varepsilon \rho \text { oф } \\
\chi \varepsilon \lambda \lambda \lambda \sigma\end{array}$} & \multicolumn{3}{|c|}{ 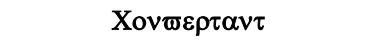 } & \multicolumn{3}{|c|}{ 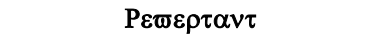 } & \multicolumn{3}{|c|}{ 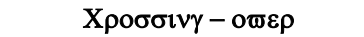 } \\
\hline & & $\mathrm{M} \nu \tau \Phi \rho \varepsilon \theta$ & $\mathrm{T} / \chi$ & $\Delta . \circ \phi \mathrm{A} \chi \tau$ & M $\tau \tau \Phi \rho \varepsilon \theta$ & $\mathrm{T} / \chi$ & $\Delta . \mathrm{o} \phi \mathrm{A} \chi \tau$ & $\operatorname{M\nu \tau } \Phi \rho \varepsilon \theta$ & $\mathrm{T} / \chi$ & $\Delta . o \phi \mathrm{A} \chi \tau$ \\
\hline Xоv $\tau \rho \circ \lambda$ & 17084 & $14.1(24)$ & 1 & - & $11.7(20)$ & 1 & - & $16.4(28)$ & 1 & - \\
\hline 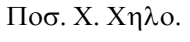 & 4642 & $189.6(88)$ & 13.4 & ++ & $155.2(72)$ & 13.2 & ++ & $336.2(156)$ & 20.5 & ++ \\
\hline Прот. & 13650 & $53(73)$ & 3.8 & + & $140.6(192)$ & 12 & ++ & $112(153)$ & 6.3 & + \\
\hline Хон $\beta \iota v \varepsilon \delta$ & 9852 & 93.5(97) & 7 & + & $151.2(149)$ & 12.9 & ++ & $106.5(105)$ & 6.5 & + \\
\hline
\end{tabular}

Key : Cons.= Concentration , Mut.=Mutation;

D. of Act $=$ Degree of activity ; Number between

Parentheses represents actual colony counts; $\mathrm{C}=$

Control value $; \mathrm{T}=$ Treatment value; $+=2-10$ control

Level;++=>10 control level;-=non significant;prot=

Protocatechuic acid;Pos.c.chlo=positive control

(chlcrpyrifos).

\section{References}

1. Abdallah, M. D., Zaazou, M. H.; Ali, A. M. and Rizkallah, M. R. (1973):Cholinesterase and aliesterase activity of different stages in the life cycle of organophosphorus resistant and susceptible Spodoptera littoralis (Boised). Bull. Ent. Soc Egypt. Econ. Ser., 7: 222-228.

2. Ahmed, E.S.; Asal, N. M. and Baeshen, A. (1999): Study of the single and combined genotoxic effects of furadan and lead in Saccharomyces cereviciae. Alex. J. Agric. Res., 44 (1): 153-170.

3. Altwaty, N.H. (1999): Genetic toxicity of insecticide chlorcyrin in Saccharomyces cerevieiae. Delta. J. Sci., 23 (1): 523-263.

4. Anderw,P.O(1997): Vitamins as antimutagens. Advantages and some possible mechanisms of antimutagenic action.Mut Res.,86:39-97.

5. Anjaria, K. B. and Rao, B. S., (2001): Effect of caffeine on the gentoxic effects of gamma radiation on 4- NQO in diploid yeast. J Environ pathol Toxicol Oncol., 20 (1): 39-45.

6. Anuradha,V.,Herman,E.B.and Vernon,W.M.(1996):Utility of a test for chromosomal malsegregation in Saccharomyces cerevisiae strain D61.M for the detection of antianeugens:test of the model combination of chlorophyllin and nocodazole.Mut.Res.,358:73-80.

7. Bear,W.L.and Teel,R.W.(2000): Effects of citrus flavonoids on the mutagenicity of heterocyclic amines and on cytochrome $\mathrm{P}$
4501 A2 activity .Anticancer Res; 20(58):3609-14.

8. Brusick,D.(1980):Principles of Genetic Toxic.Plenum press, New York,p. 2790.

9. Buschini, A.; Poli, P. and Rossi, C. (2003): Saccharomyces cereviciae. as an eukaryotic cell model to assess cytotoxicity and genotoxicity of three anticancer anthraquinone. Mut. 18 (1): 25-36.

10. Buschini, A.; Carboni, P.; Furlini , M.;Poki, P. and Tossi, C. (2004): Sodium hypochlorite, chlorine dioxide and peracetic acid induced genotoxicity detected by the Comet assay and Saccharomyces cereviciae D7 tests. Mut. 19 (2): 157-162.

11. Edenharder,R. and Grunhage,D. (2003): Free radical scavenging abilities of flavonoids as mechanism of protection a gainst mutagenicity induced by tert-butyl hydroperoxide or cumene hydroperoxide in Salmoela typhimurium Ta 102. Mut . Res., 540(1) :1-18.

12. EI- Adawy, R. A., Abd EI-Naby, W. N.,Hassanein, S. H.,Shawki, A. S. H. and Salam, A. Z. EI- Abidin (1988): Mutagenic potentiality of triazophos, sumithion, fenpropathrin and amitraz in yeast, Saccharomyces cereviciae XLX Annual Conf. Soc. Genet., Egypt, pp. 125-123.

13. Giorgio,B.;Clara,D.C and Alyaro,G. (1992): Antimutagenicity in yeast.Mut. Res., 267:193-200. 
14. Horcajada-Molteni, M.N., Crespy,V., Coxam,V.,Davicco,M.J., Remesy,C.and Barlet,J.P. (2000): Rutin inhibits ovariectomy-induced osteo-penia in rats .J.Bone Miner Res ., 15(11):2251-8.

15. Kayoko,S.,Shuichi,M.,Bingrong,S.,Mich iyo,F.and Naohide,K.(1996) Radioprotective effects of antioxidative plant flavonoids in mice.Mut.Res.,350:153-161.

16. Mansour, S. A.; Hassan, A. H. M.; Awad,A. A. M. and Salam, A. Z. EIAbidin (1988): Allozyme polymorphism in Drosophila: Induction of polymorphism in a homozygous enzyme strain under the effect of the three different organophosphorys compounds. Proc. $2^{\text {nd }}$ Conf. Agric. Develop. Res., Ain. Shams University, Cairo, 1: 237-250.

17. Nafei, H. A.; Hassan, A. M.;Mansour, S.A. and Salam A. Z. EI-Abidin (1984): The mutagenicity of organophosphorus insecticides in D. Melanogaster. Proc. $2^{\text {nd }}$ Mediterranean Conf. Genet. Cairo, 717725.

18. Nakatani,N.(1990): Recent advances in the study on natural antioxidants.Nippon Shokuhin Kogyo Gakkaishi.,37,569-576.

19. Rahman.M.F.,Mahboob.M.,Danadevi,K .,SalehaBanu,B.and Grover.P.(2002): Assessment of genotoxic effects of chloropyriphos and acephate by the comet assay in mice Leucocytes. Mut. Res.,2b;516(1-2):139-47.

20. Salam A. Z. EI-Abidin; De-Hondt, H. A.; Fahmy, M. T.; Soussa, S. F.; Elnagar, T. F. K and EI-Din Ahmed, E. S. (1995): The mutagenicity of Nudrin and Meothrin on two different eukaryotic systems Drosophila and yeast. Annals. Agric. Sci., Ain Shams Univ., Cairo. 40 (2): 737-751.

21. Salam A. Z. EI-Abidin; Ebtissam, H. A. Hussein; Hanaiya, A. EI-Itriby;
Wagida, A. Anwar and Mansour, S. A. (1993): The mutagenicity of Gramoxone (paraquat) on different eukaryotic systems. Mut. Res., 319: 89-101.

22. Salam A. Z. EI-Abidin; Hassan, A. H. M.; Nafei, H. A. and Mansour, S. A. M. (1984): Isozyme polymorphism in Drosophilo 5. The effect of two organophosphorus compounds on the gene frequency and the repair system. Proc. $2^{\text {nd }}$ Mediterranean Conf. Genet. 11 :701-716.

23. Shimoi,K.;Masuda,S.;Shen,B.;Furugori ,M.andKinae,N.(1996): Radioprotective effects of antioxidative plant flavonoids in mice . Mut . Res .,350:153-161.

24. Siebert, D. and Elsenbrand, G. (1974): Induction of mitotic gene conversion in Saccharomyces cereviciae by NNitrosated pesticides. Mut. Res., 22: 121126.

25. Stagos,D.,Kazantzoglou,G.,Magiatis,P., Mitaku,S.,Anagnostopoulos,K.and Kouretas,D.(2005): Effects of plant phenolics and grape extracts from Greek varieties of Vitis vinifera on Mitomycin C and topoisomerase I-induced nicking of DNA. Int.J.Mol., 15(6) :1013-22.

26. Steinmetz,K.A.and Potter,J.D.(1991): Vegetables, fruits and cancer. I.Epidemiology,Cancer. Causes Control:2,325-357.

27. Undeger,U.,Aydin,S.,Basaran,A.A.and Basaran,N.(2004): The modulating effects of quercetin and rutin on the mitomycin C induced DNA damage . Toxicol.Lett ., $\quad$ 151(1):143-9.

28. Zimmermann, F. K; Kern, R. and Resenberger, H. (1975): A yeast strain for simultaneous detiction of induced mitotic crossing over. Mitotic gene conversion and reverse mutation. Mut. Res., 28:381-388. 


\section{Ekram,S. Ahmed}

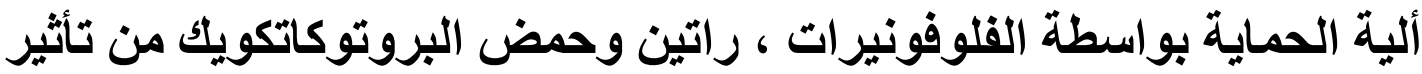

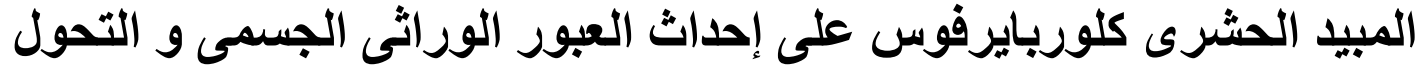

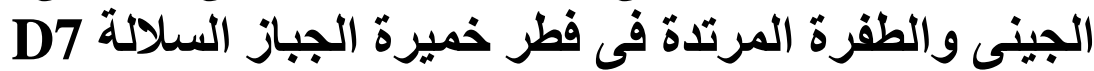

$$
\text { إكرام صلاح الدين أحمد المداه }
$$

قسم بيولوجيا الخلية ، المركز القومى للبحوث ، القاهرة ، جمهورية مصر

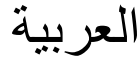

الية الحماية بو اسطة الفلوفونيدات ،ر ايتن وحمض البروتو كاتكويك من تأثير المبيد

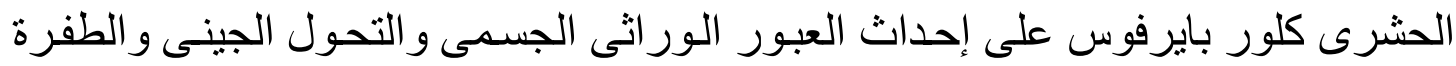

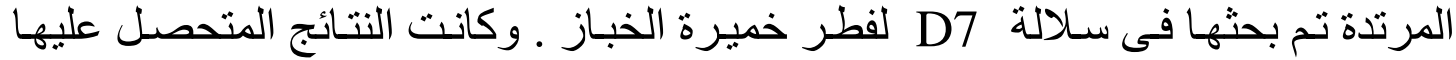

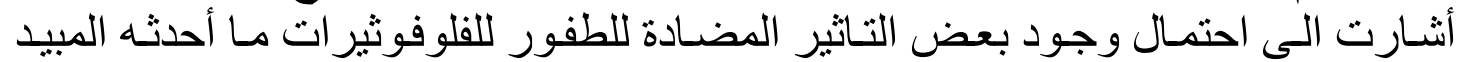
الحشري كلوربايرفوس من طفر ات لذاتلك الفلوفونير الكات المستخرجة من نبات السنا قد تلكون

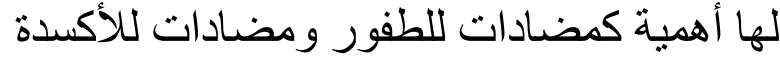

